\title{
Workshop of the Commission of the European Communities on Ethics of Human Genome Analysis: Survey of the European Discussion
}

This important EC workshop took place on 11 to 14 September 1992 in Tubingen, a delightful south German university town where one third of the population are students. It was organised by Hille Hacker, Dr Klaus Steigleder, and Professor Dietmar Mieth of the Centre of Ethics in the Sciences and Humanities. The 60 participants included eminent philosophers, theologians, ethicists, lawyers, social scientists, and medical geneticists from EC and adjoining countries. Since it was not intended that a formal statement be issued, the following is a personal compilation from five participants bringing viewpoints from ethics, medical genetics, philosophy, social science, and theology.

To many participants the essential problem to be addressed by the workshop was posed by the chairman, Dr Klaus Steigleder, who asked: "Is genome mapping compatible with individual freedom?". However, others were equally concerned with using the medical applications to relieve or prevent suffering. The scientific community looked to ethicists for assistance in reconciling these issues. An ethicist-theologian at the workshop maintained that he did not have a monopoly on ethics, but hoped to shed light and facilitate communication among participants who might then be better able to give specific attention to what is good or right in human life. Such an interdisciplinary ethical interest was evident and the variety of approaches, from biology, social sciences, and philosophy, and also the different medical and cultural contexts in European countries contributed to the general diversity of the workshop.

\section{The philosophical context}

Contributions from philosophers emphasised general issues. These concerned human dignity, the affirmation of individual freedom despite biological determinants and social constraints, the right balance between the quality of human life and its sacredness especially at its beginning, and the elucidation of real ethical questions concerning eugenics. Philosophers recognised that they must avoid an unnecessarily sensational and threatening

To be published at the end of July 1993: Ethics of human genome analysis, European perspectives, Steigleder K, Hearn R, eds, in the series Ethik in den Wissenshaften. Tubingen: Attemto Verlag. vision of genetics. They must also get nearer to the 'sharp edge' where advances may be implemented through the network of medical, familial, social, and economical relationships. In so doing they must define what is specific to genetic knowledge and power, for example, the fact of receiving and transmitting genes, with their qualities and defects, from and to other humans. Genetics compels us to broaden our horizons beyond isolated persons in a society, and to consider families. To be a son or daughter, a father or a mother, while being also a fellow person, represents a responsibility which transcends personal autonomy.

\section{Medical genetics}

Although there were several presentations (from the Netherlands, Switzerland, and the UK) describing health service genetic centres, discussion of them was limited by disagreement over the meaning of words like health, predictive medicine, abortion, and eugenics. Clinical geneticists had difficulty accepting the apparent rejection, or at least delay, of medically important advances because of semantic difficulties and the inchoate fear of theoretical dangers. There were many attempts to bring the discussion back to the human genome project but at no point did a consensus emerge whether this was a 'good thing' or not, and some topical issues, including germline therapy, received little attention.

Few at the workshop objected to the cost of the human genome project but many believed that it was a precursor to an inevitable return of eugenics because it would provide the rigorous science and practical techniques necessary in large scale public health strategies. Participants from the Netherlands and UK showed how a network of genetic centres, coupled with public education, provide the best protection against neo-eugenics. Properly funded genetic centres are regulated by their multidisciplinary composition and independent ethical advice. However, trained medical geneticists are few and the sheer mass of potential health and disease prevention applications will thrust increasing responsibility on a medical profession ill prepared either by training or inclination. Improving professional education is thus a matter of great urgency. Furthermore, new tests and treatments arising from the human genome project must be rigorously evaluated (validated) before widespread implementation. 
This requires an adequate research and development budget. The British national Confidential Enquiry into Counselling for Genetic Disorders was cited as a means for assessing skills and resources, and for educating nongenetically trained doctors.

\section{Semantic problems and the threat of neo-eugenics}

Throughout the workshop a persistent concern was with the "... dark shadow of eugenics ... falling upon the human genome project and upon genetic diagnosis...". Although only one language was used (English), it took four days for the participants to begin to understand one another. Familiar terms like 'health' and 'quality of life' had no simple definition that all could accept and it was pointed out that such apparently worthy concepts as 'quality of life' might be 'eugenic' if used as a basis for prenatal selection. Numerous definitions of 'positive eugenics' and 'negative eugenics' were proposed and rejected. One social scientist noted that prenatal diagnosis led to abortion of genetically handicapped babies and is properly described as 'eugenic'. Other participants disagreed. To them 'top-down eugenics' was the main threat and implied public health measures designed to improve the gene pool of entire populations, with a locus of control in the state, rather than in individual reproductive decision making. They believed that the increasing availability of effective genetically based prenatal tests can reasonably be expected to contribute to responsible individual decision making with regard to reproductive choice. However, the growth of commercial testing was lamented by medical geneticists as well as consumers and patient organisations who feared an increase in uncounselled tests. Adding the fact that an increasing number of women outside the medically established risk groups are pressing for diagnostic tests ('angst' indications) led a social scientist to wonder whether 'bottom-up eugenics' is a more likely problem where persons will use/abuse the expanding test market to increase their control over sex selection, abortion of fetuses with minor handicaps, etc.

It was interesting to see that substantive issues, such as the feared link between human genome analysis and eugenic strategies, could be dealt with satisfactorily by definitions and conceptual stipulations. However, it became painfully obvious that, even if agreement could eventually be reached within the scientific community on the 'proper' meaning of terms, like 'eugenics', the lay public would continue construing the issue in its own terms. Science regulates public debate about deeply controversial issues to a much lesser extent than many scientists believe. The expert, in order to contribute to the education of public opinion, cannot simply teach what, from his or her point of view, are the 'facts'. He or she will have to listen, and take seriously, what appears to him or her as confusion or 'fiction'. This requires good communication skills, not only good science.

\section{Genetic determinism}

A similar point of general importance emerged concerning 'genetic determinism'. This supposes that if you know enough about genetic make up you will know everything worthwhile about a human being. Sometimes there is an even stronger claim in this view - that genetic information will purchase you all the predictive power you want with regard to every important physical and psychological trait of an individual person. This was hotly rejected because participants believed that the 'hard' facts of the biological sciences, psychology, and sociology do not support genetic determinism and human beings are capable of free choice and are not rigidly confined by the genome, even when combined with early environmental experiences. One participant explained at length that genetic determinism is not even a live option for coherent philosophical thought experiments. Nevertheless, the spectre of genetic determinism haunts the minds of many people especially in countries where opposition to genetic technology is fierce, as in Germany. It would be arrogant and imprudent for the 'expert' to ignore this on grounds that he or she knows better. A more enlightened stance (as in the eugenic debate) is to listen to the lay public's discourse charitably and perceptively, even though this may occasionally take something like a 'third ear', in order to discover the fears and concerns that dress up in pseudoscientific cloth.

In contrast there are entirely legitimate worries about who will control the information that will be made available through advances in genetic testing. Who will determine how benefits and costs resulting from the impact of such information on the health insurance sector or the work place will be distributed? It was suggested that publicly expressed worries about 'genetic determinism' were actually concerns about information abuse, and that this is worth investigating.

\section{Human autonomy}

Human autonomy was hotly defended. However, the debate was about essentially social issues, including conflicts between individual, medical, and commercial interests. The potent new genetic technology not only creates difficult options for patients and medical doctors, it also transforms the social relationships of the medical world by redistributing power and redefining concepts of normality and disease. One outstanding and perhaps unsolvable issue was whether the right not to know was to be respected in all instances since this right sometimes clashed with other persons' right to know. The fact that genetic information by 'nature' is not individual and private, but actually a mutual feature of members of the same family created dilemmas that could not be resolved within the individual centred ethical paradigm of informed consent. Some geneticists suggested that decision making should be made in accordance with so called responsible reproductive behaviour to avoid unnecessary harm, for example, to children of 
Huntington's disease patients or persons at risk for HD. No-one had solutions to these dilemmas which were examples of the reshuffling of social power and obligations that are created by genome mapping. This made very relevant the suggestion that ethical assessments ought to be implemented at a very early stage of the scientific and technological innovation process, a proactive ethical technology assessment (see below).

\section{A social scientist's model}

It might make it easier, a social scientist suggested, to regard the 'actors' in the play (doctors, patients, researchers, ethicists) as representatives of social and institutional interests. These interests are embedded in specific social networks or scientific traditions or both and one should interpret their value, views, and actions correspondingly. Such basic issues were not addressed at the workshop although C P Snow's Two Cultures was referred to several times.

\section{Genetic counselling}

Non-directive (non-coercive) genetic counselling was agreed to be the gold standard and there was a strong view that genetic testing procedures should not be permitted without counselling and should not be made freely available on a medically unconstrained commercial basis. However, one geneticist contested this consensus, making a strong point for deregulation. He argued that the individual person's interests will be served best if genetic tests were made a market commodity. There was not much common ground as to what are the best standards for, and models of, genetic counselling. It was not clear whether the group felt that counselling should be obligatory or should be available on request by the client. It was also unclear as to how the much avowed principle of 'non-directive counselling' relates to the bioethically uncontroversial principle of 'informed consent' if the latter requires revealing 'normative commitments' on behalf of both the client and the counsellor.

Non-directive counselling, a concept that originated in the humanistic 'client centred psychotherapy' of Carl Rogers, cannot absolve the counsellor from being accountable for his or her value orientations with regard to the range of choices that are the focus of his or her counselling. Hence, an ethics of (genetic) counselling is very much to be desired. Such an ethics would have to provide an intelligent normative response to two related moral pitfalls of counselling: outright abrogation of individual moral responsibility ("it's all up to the client"), and an all out value relativism ("de valores non est disputandum").

\section{Economic factors}

It was emphasised that there are important economic factors, including the adequate funding of ethically acceptable genetic health services. Other issues include the growing problem of genetically compromised persons obtaining life and health insurance, and of work place testing. Insurance companies are expert at assessing risks and are driven by economic factors. Similarly, work place genetic testing may be beneficial in helping to prevent industrial disease, but both insurance and work place testing will eventually lead to discrimination of the genetically 'unfortunate'. Such economic factors (and the discrimination they bring) could only be mitigated, it was argued by a Dutch participant, by legislation including a government safety net providing financial compensation to those disadvantaged.

The different attitudes of the US, UK, and French authorities to patenting the human genome were discussed and the consensus was that such patenting was unacceptable. However, innovative products resulting from research are arguably within the realm of patent law and indeed encourage governments, research institutions, and commercial concerns to invest money in this area. Licensing agreements allowing researchers cheap access to these products was an acceptable compromise to some.

Many participants were seriously concerned about intellectual property rights. Competition fuelled by economic interests threatens to disrupt the trust, transparency, and cooperation that are necessary preconditions of scientific work. This is especially true of scientific work carried out on a grand scale requiring international cooperation within the global scientific community.

\section{Conclusions}

Unfortunately, four days were insufficient to resolve the considerable differences between the disciplines represented. It did not allow the philosophers fully to join the geneticists in their desire for practical outcomes nor did it allow the pragmatists to do more than sense the intellectual challenge presented by the superb philosophical debate. Research scientists tended to think expansively and see the problems of genome analysis as a challenge ("therapies will eventually develop, even if we don't seem to be able to get anywhere at the moment, the opportunities are fantastic"). In contrast theologians and philosophers tended to be more restrictive thinkers focusing on the risks and fears generated by genome mapping. Will tolerance of deviant behaviour and deviant medical status be reduced as a result of biologically based discrimination? Some sociologists argued that the medical paradigm was often inappropriate ('shroud waving') and was transcended by the need to anticipate, and thwart, misuse of new knowledge. Medical geneticists are in the middle burdened by practical clinical issues. It was agreed that there was an urgent need for proactive ethics to set up testable hypotheses regarding human autonomy, confidentiality, non-directive counselling, choices, the right to know, and the proposition that there should be "no testing without counselling".

Regretfully, two disciplines, law and eco- 
nomics, were missing from the workshop although their contribution would have been important in identifying some of the practical restraints on the human genome project.

AN INVESTIGATIVE APPROACH

Greater insight into these ethical problems requires more data from human life sciences. For example, the right not to know calls for more psychological research since knowing or not knowing a genetical fact concerns one's destiny and one's origin. How far do such revelations disturb or favour one's ability to give sense to one's life? Studies of the outcomes of genetic counselling seem indispensable to the concrete consideration of this kind of ethical problem. Sociological and institutional analyses of the actual functioning of genetics might resolve some of the confusion about responsibilities. This kind of investigation could be usefully developed for those, politicians or administrators, who are in a position to make social choices with respect to genetic medicine.

For those without formal ethical training who wished to consider an investigational approach, it was valuable to have a clear definition of an ethical framework. This distinguished 'meta-ethics' (the language of morals) from 'normative ethics' (the investigation of values and norms in both virtues and attitudes and in the justification of actions). 'Actions' we were then told are of three types: 'tragic cases' (when, for example, one can save one human life only at the expense of killing another), 'comparative cases' (calculating the consequences of actions or omissions), and 'categoric cases' (intrinsically wrong, for example, rape and torture). Most controversial issues regarding the human genome project can then be investigated by considering five areas.

(1) Basic ideas. What are the conditions under which we can accept the human genome project as a good thing?

(2) Basic attitudes. How may the project affect our attitudes to life, disability, minorities, and also to fundamental concepts of freedom and autonomy?

(3) Medical doctrines. How will the doctorpatient relationship, systems of health care, disease prevention and cure be affected and how will we achieve a free flow of information and counselling?
(4) Optimisation. How would we cope with a recrudescence of eugenics and attempts to 'optimise' the human gene pool in a search for human perfection through genetic manipulation. What will be accepted as 'normal' and 'natural'?

(5) Social, economic, legal, and political. How will we grapple with implications of innovations, the effects of market forces in scientific progress, patenting, copyright, insurance, mass screening, data protection, etc?

These questions require urgent answers if we are to achieve an acceptable compromise between the responsible use of the results of the human genome project and the unacceptable manipulation of genes and people. There is a need for highly pluralistic, democratic institutions in which discussion may lead to widely accepted agreement. For this to be achievable we must have an 'ethics of terminology' to end the semantic confusion which this workshop has so clearly illustrated. When this has been achieved we may have some hope of tackling the questions in the above five areas (or more) within an ethical framework such as that suggested earlier. The final goal of these proceedings might be a 'Genetic Bill of Rights', that is, an explicit statement of protections and duties to try to guarantee human self-determination in spite of an increasingly transparent genome.

Whatever the outcome of the ethical debate, one group is sure to be profoundly affected by the application of genome mapping. Medical geneticists and genetic counsellors will experience an enormous increase in the demand for their services as our concept of disease becomes increasingly 'geneticised'.

OLIVIER DE DINECHIN SJ Departement d'Ethique Biomédicale, Paris, France. RODNEY HARRIS

Department of Medical Genetics, St Mary's Hospital, Manchester M13 0FH, England. MATHIAS KETTNER

Department of Philosophy, Frankfurt, Germany. LENE KOCH

Institute of Social Medicine, University of Copenhagen, Denmark. EDUARD ZWIERLEIN Universität Kaiserslautern, Germany. 